\title{
TALL STRUCTURES RETROFITTING, ERECTION AND STABILITY
}

\author{
P. Surya Prakash, M.S. \\ (Civil Engineering), IITM, India,
}

\begin{abstract}
Infrastructure for mobile communications has grown rapidly in the last two decades across world particularly more in India. The Technology upgrade and multiplying volumes called for retrofitting the existing infrastructure. Last two decades 250,000 towers were installed in india by individual service providers (SP) of mobile communications. The number of users has grown to $300 \mathrm{Mn}$ and about 6 major SP. The competition among SP has brought in pressure to bring down the cost of infrastructure. This resulted in sharing of infrastructure already built by 2 to 6 SP. Communication towers, in addition to main supporting structure, have many accessory sub structures such as ladder, cable tray, platform etc. The computation of drag coefficient though detailed in Indian code is not very specific to the application. Although British code has dealt with accessories, it is again an approximation. The towers in India are primarily self-supporting steel lattice towers of heights ranging from 40m to 100m. They are composed of sections All Angles, All Tubes or Hybrid with bolted connections. The method of retrofitting is by additional member support.
\end{abstract}

Keywords - Lattice Tower, Retrofitting, Hybrid, DELTA Tower, RTT, GBT, TowerCAD

\section{INTRODUCTION}

In now a days mobile communication towers has grown very rapidly due to the increasing number of users around the globe. Frequent technology upgrade like $2 \mathrm{G}$ to $3 \mathrm{G}, 3 \mathrm{G}$ to $4 \mathrm{G}$ and multiplying volumes of mobile users. In order to maintain these users Service providers were installing the number of communication towers. It is difficult and not viable to multiple number of mobile sites and COAI (Cellular Operators Association of India) has agreed to share the infrastructure. There were off shoots of infrastructure companies who would build, operate and lease these sites and have taken over existing infrastructure of these operators where the infrastructure designed to service individual operators. The single operators have become first tenant of the site and infra companies started to plan to offer these sites to multiple tenants and they would in turn need to increase in loading in terms of GSM/CDMA/MW antennae. Such needs have called for retrofitting the existing tower infrastructure which are classified as tall structures as the heights range from minimum $15 \mathrm{~m}$ to $100 \mathrm{~m}$ in height and primarily wind load resisting structures. As the competition among service providers resulted in sharing of infrastructure due to the cost of installation. Even though the infrastructure was made but due to the natural disasters these infrastructure i.e., communication towers are going to face failure phenomena. Whenever the tower failure happens it was mainly due to the stability issue or a lack of skill. In order to get high stability of the structure or a tower it needs to be modified while designing or it should be retrofit after the construction.

The towers are broadly classified into 4-Legged Angular, 3L Angular, 3-L Tubular, 3-L Hybrid, 4-L Hybrid, DELTA Tower (Tower in Triangle), Hexagonal Base, Octagonal Base etc. Based on installation they are classified as Roof Top Towers (RTT) and Ground Based Tower (GBT). Hybrid towers are designed using circular pipes as main leg member and angles as bracings. Communication towers, in addition to main supporting structure, have many accessory sub structures such as ladder, cable tray, platform etc.,

\section{LOADS}

The Loads considered on towers are Self Weight (SW), Wind on tower, wind on ladder, cable tray, plat form, wind on antennae. In the computation of wind load on an antenna taking the effective projected area actually didn't give the exact wind load on that specific antenna. In IS:875-Part 3 Clause 6.3.2.2 and 6.3.3.2 (a) didn't mention the reduction factor $\mathrm{k}$ for structural members. It is not possible to find the exact wind load acting on the microwave antenna which is circular with concave inwards in shape on a specific height by using the IS Codal provisions and even British code also didn't give the exact wind load acting on it, it's also giving the approximate wind load value.

\section{RETROFITTING}

Retrofitting explains causalities, precautions considered in the fabrication enterprise to grant fresh or modernize parts that can be fixing to the outdated parts. In towers, in order to subdue failures, an extra leg member is added adjacent to the old leg in such a way that the additional force when the original member exceeds its capacity is transferred to the new member. This measure will prevent failure and enhance the capacity of the tower but needs periodic maintenance to check any plastic hinges formed in the original leg member. The type of steel sections to be added and the number of antennas recommended are interred governed by each other. When a tower is subjected to failure, it may be the reason due to the overload of antennas and it is not possible or a good idea to remove the antennas from a tower as the purpose for a tower installation would be useless. In order to balance the loads from antennae, the leg sections are to be retrofitted by recommended sections to obtain suitable factor of safety. On the other hand, after the legs have been added 
to balance the forces, it is the role of a design engineer to check whether tower has got the ability to bear extra antennas and the behavior of a tower prior to and after strengthening can be clearly explained from the analysis.

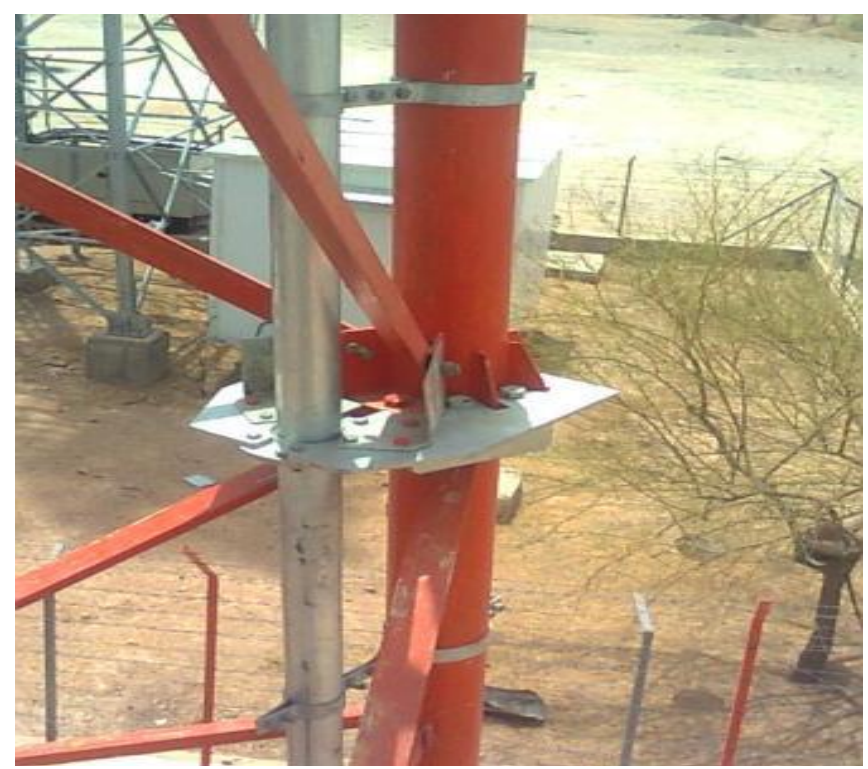

Figure 1: Split flange stiffened coupling plate

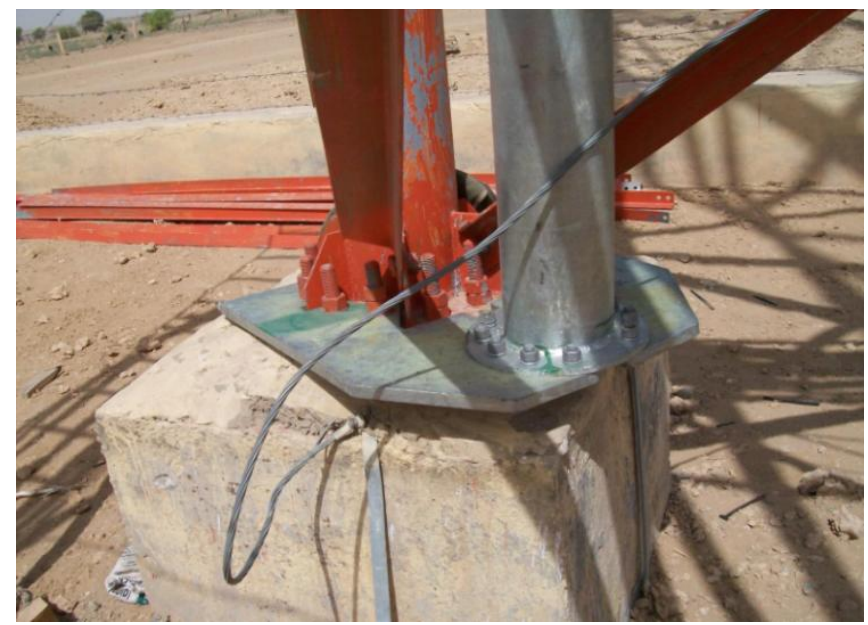

Figure 2: Base plate coupling

Strengthening of a transmission tower will include adding or replacing steel members on the tower as well as reinforcement work. Retrofitting of transmission line tower includes plinth level stub corrosion, strengthening of leg members, strengthening of bracing and strengthening of foundation.

The piece of bottom most leg member, which is embedded in to the foundation is called stub. The stub is transfer the load coming from the tower to foundation. The extent and rate of corrosion depend on the nature of the environment as well as on the nature of metal or alloy. The decreased section and the accompanying stress concentrations correspondingly reduce the load bearing capacity of the member.
The main cause of leg member fail is wind. Due to wind load the leg members are subjected to compression and tension as well. To resist the tension developed there must be sufficient strength in legs and connection between the legs. The main cause for the failure is either due to the inadequate no. of bolts at the failure joint or insufficient strength of the bolt provided at that joint. The generally adopted measure is adding by extra angles or adding redundant.

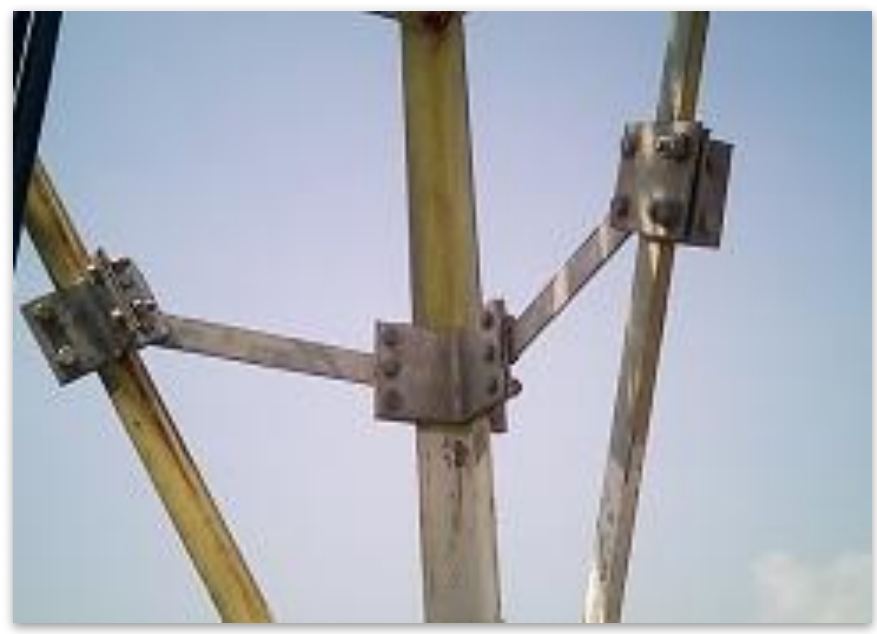

Figure 3: Main Leg Strengthening

In GBT Hybrid towers new tubes are connected to the existing tube using the splice bolts in the flange connection. Two coupler plates which are stiffened enough to transfer by flexure and shear resistance are used at every splice flange plate connection. Half the bolts are opened and one coupler plate is added. Second plate is added after opening the balance half of bolts while the first set is already fixed. Bothe the coupling plates extend to connect to the flange plate of the new tube. The effective length of the new tube is restrained by using friction clamp at regular interval. Similar concept is used to connect to the existing base plate.

In most of the RTT failures are reported to be because of base anchor failures hence it is adopted using the guy rope solution.

In GBT Angular towers are strengthened using additional angle again connected to the existing leg by using bolts in splice and other joints.

After it is established that the foundation is unhealthy, it is better to strengthening the foundation. Due to wind load the column are subjected to compression and tension as well. To resist the tension developed there must be sufficient lap length between the bars. Cause for the failure is due to the inadequate or no lap length at the joint. If sufficient lap length is not available, welding must be done for a sufficient length. Foundations are designed for critical loading if high seismic zones tie beams are provided to prevent the differential settlements. The generally adopted measures are providing tie beam, or by ground improvement techniques. 


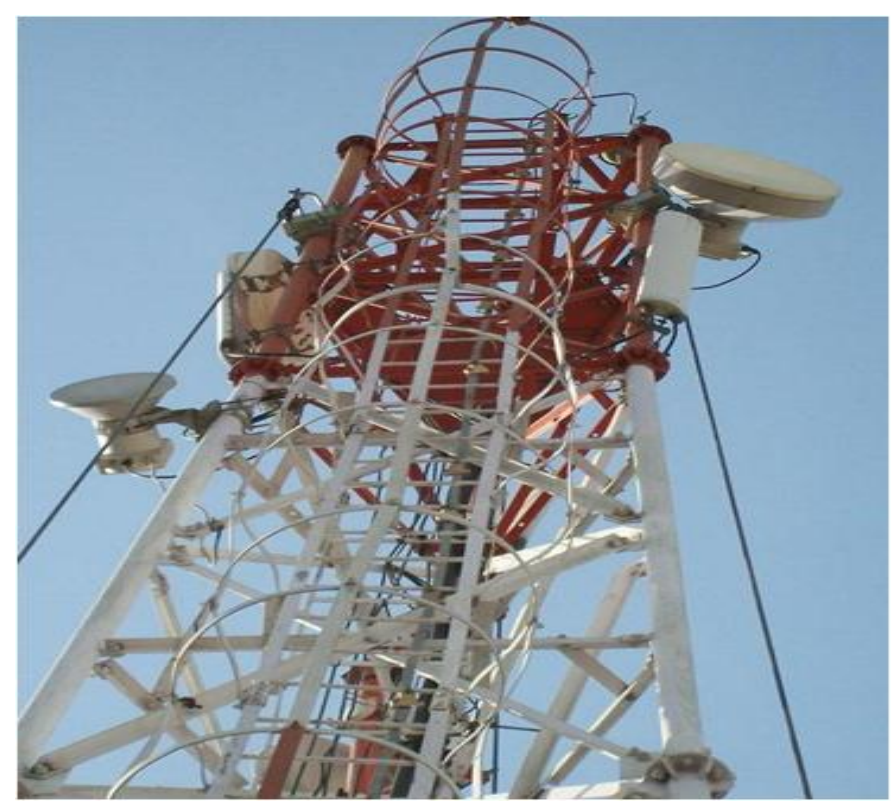

Figure 4: RTT strengthening using guy ropes

Portal model was used for the analysis to check force in new member. According to the analysis and design experience with the strengthening, a tower can withstand the additional forces from antennas without disturbing the main supporting structure.

In general, the tower is idealized as a space truss and modelled in TowerCAD according to the configuration and details of the members provided and analyzed for various load combinations. The members are designed for maximum tension and compression forces for most critical load combination as obtained from analysis, based on type of member category for design based on standard specifications. The analysis for getting the force in new member shall be done by providing hinge joint at base of existing leg and fixed at the base of new member.

\section{PLASTIC ANAYSIS}

From the past century, plasticity theories \& computing technologies brought the major change and gave a path to the scientists in order to create plasticity methodologies to structures. The key element to create and accomplish the calculation methodologies for all kinds of structures was always the framed structure. There are two types of plastic analysis techniques are there for the framed structures. They are direct and step-by-step methods.

Plastic hinge creation is a very crucial part in frame structure plastic analysis. It shows great difference in not only the perfectness but also the preparation routine. In order to create or generate plastic hinges, defining of the yield surface was crucial and then deformation at the regions of plastic hinges and forces causing those deformations relation must be generated.

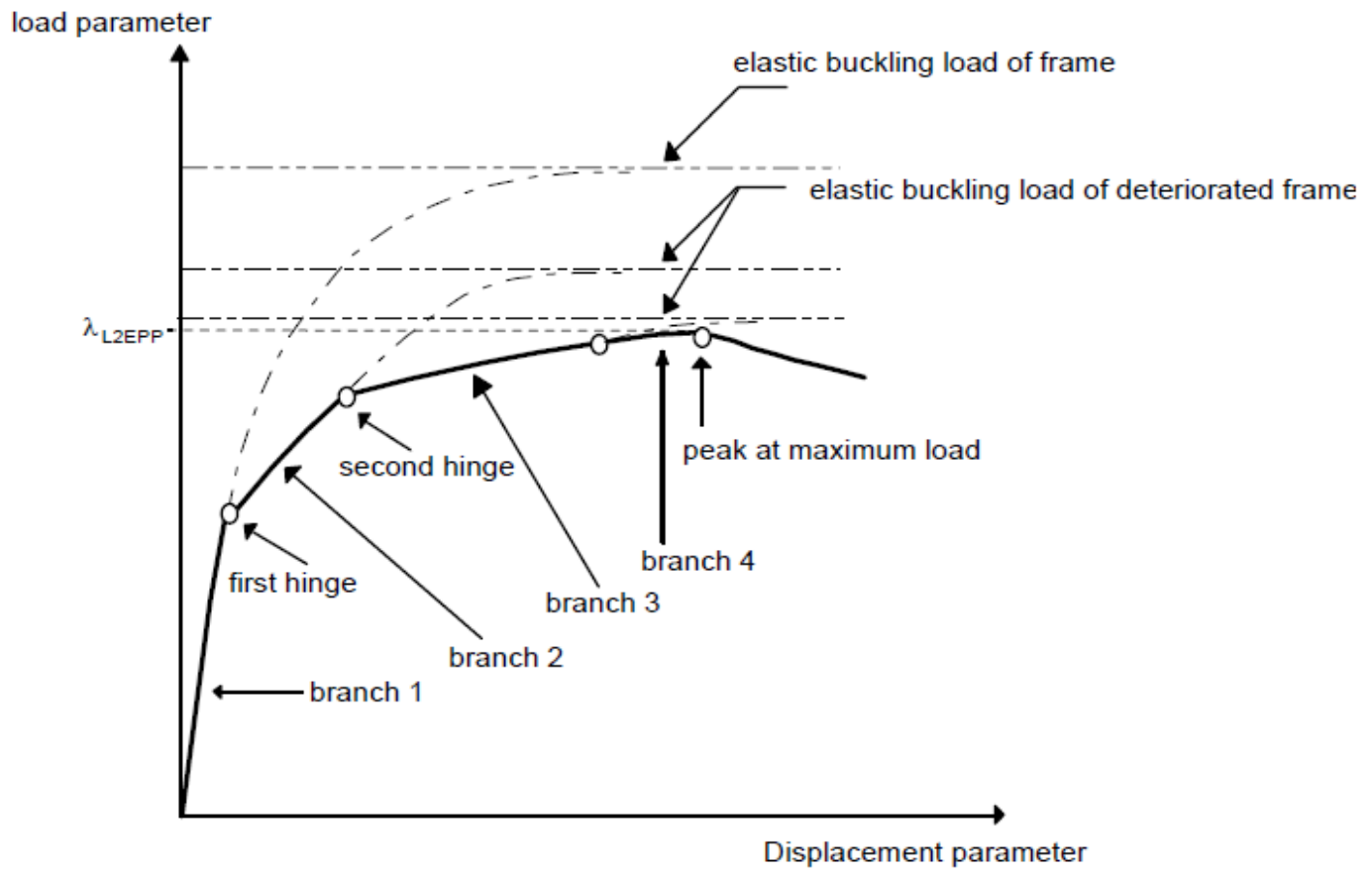

Figure 5: Load displacement response: Second-order elastic-perfectly plastic analysis

For the specific increment in the loading in order to transfer the plastic moment these joints inserted at the hinges was acts as a pin. If infinite elastic behavior occurred complete elastic curve shown in figure 5 branch 1 which is asymptotic to the elasticity buckling loading may happen. After the formation 1st hinge Frame behaves as further incremental up to the establishment/shaping of next hinge. Now by assuming the unlimited behavior of elasticity further hinges being formed until it becomes a mechanism/instability of frame. 


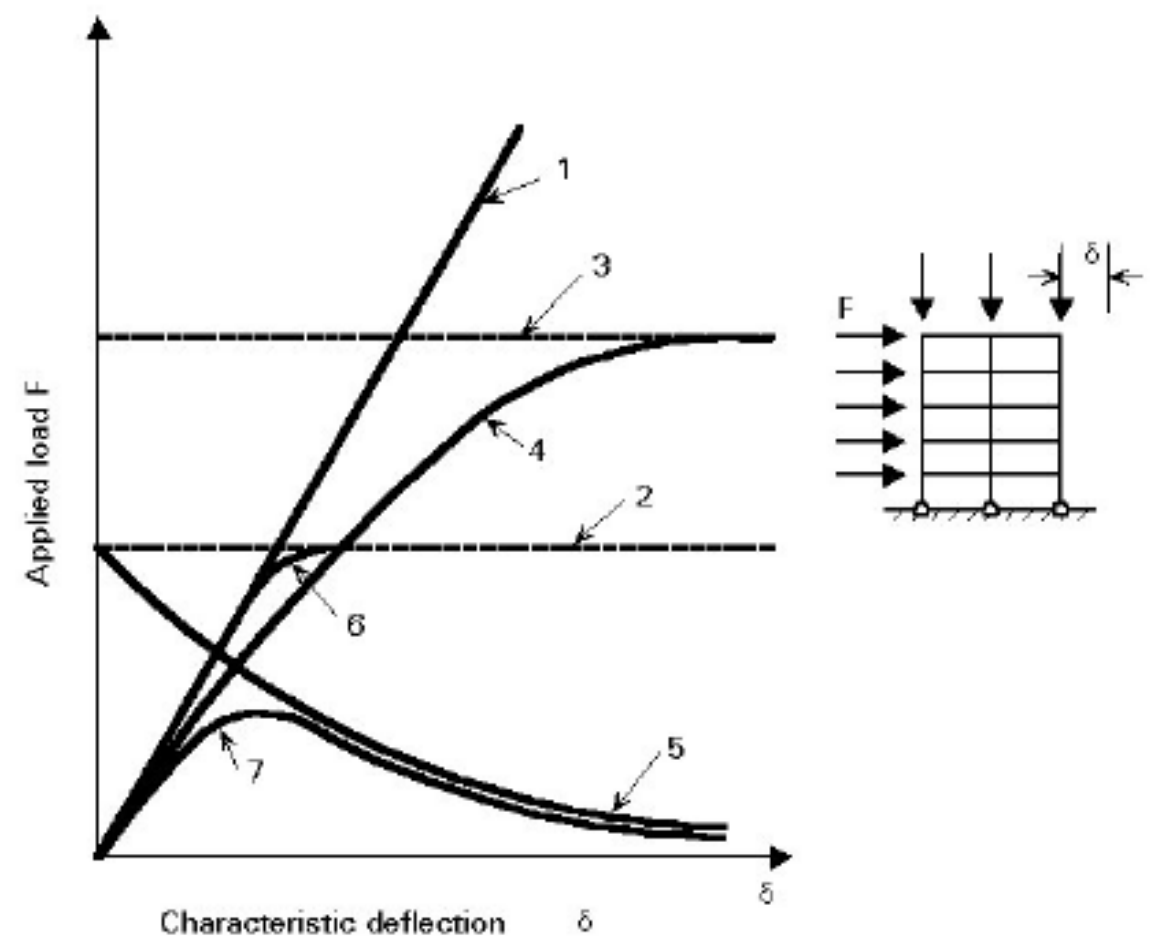

Figure 6: Frame response according to different type of analysis

In the 1 st order elastic analysis between the deformation and loading applied (F) linearity was assumed. Assumption was made that the displacement in the framed structure doesn't affected by the internal force distribution. According to the line 1 in the figure 6 frame will responds.

Rigid plastic analysis simply disregards the results occurred due to the elastic deflections \& adopt all structural distortion took place in distinct areas, known as plastic hinges (plasticity took place). Collapsing condition is addressed whenever the use of 1 st order rigid plastic theory was takes place. This collapsing condition occurs whenever the plastic hinges are all change to the whole structure in to a mechanism. The consideration of reaction of the hinge formations \& any medium distributions of internal forces won't be taken into account when the course of plastic hinge formation happened.

In Figure 6 Curve 2 represents the response of the frame related to the above condition. The amount of deflection information won't be available because of the kind of analysis. Analysis only provides that all the significant stiffness was gone at load of collapse and then the unstoppable deflection will occur.

Based on the difficulty and capacity of the particular frame, many number of buckling phenomena, where apiece with its related elastic vertical load, maybe achievable. Critical load curve representation was shown in curve 3 in figure 4 due to elastic buckling phenomena.

In 2 nd order elastic analysis consideration of result due to elastic deformation on internal force distribution was made. Now it leads to the deviation from the linear analysis line 1 at the lower loading to elastic critical line 3 at large deflections.
In second-order elastic analysis the effect of elastic deformations on the internal force distribution is taken into account. The result is a transition from the linear analysis line 1 at low loads to the elastic critical line 3 at large deflections.

The plastic analogy in the towers may give the proper guidance to understand the retrofitting to the structures. Whenever the structure reaches its plastic moment, then a plastic hinge was formed in that specific member. Usually this plastic hinge allows very large rotations. So after reaching the ultimate capacity of loading the member or particular frame may fail. In order to resist or prevent damage these frame/members may needs strengthening known as retrofitting. By retrofitting the member failure phenomena may reduce or permanently avoided.

\section{STABILITY}

The tower stability is mainly based on the performance of the leg members. the stability is also depending on the welding strength of the joint between the gussets used to connect bracings and the leg tube. A guyed mast is a tall thin vertical structure that depends on guy lines for stability. GBT structure stability will be depend upon the main leg members.

\section{CASE STUDY BY SVPCPL}

A 100 m FM tower was erected on hill top at Barmer in Rajasthan had plumb variation during erection process at nearly $75 \mathrm{~m}$ from the base level and facing the problem of further erection. The problem has been identified as improper grinding at star angles lead to erection problem. Hence temporary supports have been kept, the star angles 
have been grinded well and matched the levels. By reconnecting it on same plate. By providing the strengthening at that level results to solvation of the problem.

A $90 \mathrm{~m}$ microwave tower during erection encountered a problem. During foundation, the template provided in the drawing has been casted wrongly, in order to rectify the issue, cleat angles has been provided in bigger size without affecting the super structure.

A $230 \mathrm{~m}$ guy rope tower was faced a problem due to bending and it get fixed by giving the extra guy ropes at the level of bending.

\section{ECONOMIC \& AESTHETIC CONSIDERATIONS}

1) The expense of a steel lattice tower or a guy tower is approximately proportional to the square of their height or elevation.

2) Usually a guyed mast tower is less in cost when comparing with the steel lattice tower of same height.

3) Generally guyed mast tower needs more land since it uses guys to hold the mast in place. Since the land is major key element in the erection $\mathrm{f}$ guy towers so it usually erected in the rural regions where land is available and other un-guyed structures will be erected in very less place.

4) Usually it is less in cost to build a steel tower lattice than a concrete one which is same in their elevation.

5) Two minor towers may be invasive in looking than major tower, particularly if their appearance is same.

6) Towers may look beautiful if all the antennas and tower members al 1 are arranged in a symmetrical manner.

7) Towers made by concrete was not made according aesthetical design and they are usually present in the European continent. They are generally erected in the defined regions and which is usually includes observatories.

\section{Professional Indemnity}

Professional indemnity also known as professional liability insurance is a liable insurance which is usually guards the professional advices and service giving persons and enterprises from taking the all cost of shielding against the negligence arrogate or a claim done by client, and indemnity made in civil claim. This liability insurance meant for professionals such as architects, accountants, engineers etc. as the structure was being designed and erected if the client made a negligence claim that results to bear full cost for damage then engineer has an advantage from bearing the all cost of oppose towards that claim. Professional indemnity of professional liability insurance comes under the business insurance category.

\section{CONCLUSION}

The paper discusses the issues in loading, methods of retrofitting and stability of such structures, method of analysis and concept of erection for strengthening parts and it also discusses the issues of stability versus serviceability and professional indemnity of structural engineers.

\section{REFERENCES}

[1] Communication Towers - Design \& Implementation, SatyaVani Projects and Consultants Pvt. Ltd Co., Hyderabad, TS, 2010.

[2] Code of practice for design loads (other than earthquake) for buildings and structures (IS 875, Part 3-1987 Reaffirmed 1997 Second Revision), 1989. Bureau of Standards, New Delhi.

[3] Use of structural steel in overhead transmission line towers code of practice part 1 Materials, loads and permissible stresses (IS 802, part 1 / sec1):1995, Bureau of Indian Standards, New Delhi 110002.

[4] TIA STANDARD, Structural standard for antenna supporting structures and antennas, ANSI/TIA-222-G2005, Jan 1,2006. 